\title{
Effects of exogenous ABA on photosynthesis and stomatal conductance of cut twigs from oak seedlings
}

\author{
E. Dreyer and I. Scuiller
}

Laboratoire de Bioclimatologie et d'Ecophysiologie Forestière, INRA Nancy, Champenoux, F-54280 Seichamps, France

\section{Introduction}

Abscisic acid (ABA) plays a major role in plant-water relations. It has been shown to promote stomatal closure in many species including trees (Johnson, 1987), and there is growing evidence that it could be a root-produced effector for water stress reactions (Zhang et al., 1987). These assertions are based on studies with cut twigs supplied with exogenous $A B A$ and on measured increases of ABA concentrations in xylem sap.

However, many questions remain open to discussion: are the concentrations of exogenous $A B A$ necessary to promote a sensible reaction of the same magnitude as those of free $A B A$ measured in the xylem during water stress? Is the rapid stomatal closure promoted by exogenous $A B A$ the direct cause of the observed decline in net photosynthesis (Downton etal., 1988) or is there some direct effect of ABA on mesophyll photosynthesis (Raschke and Hedrich, 1985)? Do forest trees display the same responses to $A B A$ as other species?

We have therefore, as a preliminary to a detailed survey of the role of $A B A$ in reactions of oak species to water deficits, test- ed the reactions of cut twig photosynthesis to exogenous ABA. The effects of shoot removal on gas exchange were assessed prior to use of this technique with $A B A$.

\section{Materials and Methods}

\section{Plant material}

$3 \mathrm{yr}$ old seedlings, grown on a sand-peat soil $(50 / 50, v / v)$ in 8 I pots, were transferred into a climate chamber (February) to accelerate bud break prior to measurements conducted during March and April 1988. Species: Quercus robur Fig. 1.L., Q. petraea L. (seeds collected near Nancy), and $Q$. pubescens $L$. (Avignon).

\section{Gas exchange measurements}

These were made in an open flow chamber. Twig transpiration was estimated using a bypass flow $\left(300 \mathrm{l} \cdot \mathrm{h}^{-1}\right)$, and net $\mathrm{CO}_{2}$ assimilation was calculated from $\mathrm{CO}_{2}$ reduction in the main flow $\left(60 \mathrm{l} \cdot \mathrm{h}^{-1}\right)$. Chamber volume was $9 \mathrm{l}$; time lags between apparent assimilation and transpiration appeared during rapid rate changes. Steady state calculations were therefore only conducted after stabilization to avoid artifacts.

Climate in the chamber

Photosynthetic photon flux density: about $600 \pm 20 \mu \mathrm{mol} \cdot \mathrm{m}^{-2} \cdot \mathrm{s}^{-1}$; temperature: $24^{\circ} \mathrm{C}$; 
molar fraction of $\mathrm{CO}_{2}$ in the chamber $\left(c_{\mathrm{a}}\right)$ : $350 \pm 5 \mu \mathrm{mol} \cdot \mathrm{mol}^{-1}$; leaf to air difference in water vapor molar fraction $(\partial w)$ : about $12-15$ $\mathrm{mmol} \cdot \mathrm{mol}^{-1}$, depending upon leaf temperature and stomatal conductance. Leaf water potential $\left(\psi_{w}\right)$ was monitored in the chamber with a Wescor in situ leaf micropsychrometer.

\section{Gas exchange parameters}

Net $\mathrm{CO}_{2}$ assimilation (A), transpiration (E), stomatal conductance for $\mathrm{CO}_{2}(g)$ and mesophyll $\mathrm{CO}_{2}$ molar fraction $\left(c_{\mathrm{i}}\right)$ were calculated according to von Caemmerer and Farquhar (1981). Results are presented either as time evolution of $A, g$ and $\psi_{w}$, or as $A$ vs $c_{i}$ graphs.

\section{Twig removal}

Twigs bearing 3-4 leaves were enclosed in the chamber and gas exchange parameters determined after at least $2 \mathrm{~h}$ of equilibration. Thereafter, twigs were detached and their cut end immediately plunged into a nutrient solution. Gas exchange parameters and leaf water potential were monitored for at least $4 \mathrm{~h}$ after cutting.

\section{$A B A$ application}

(+/-)2-cis-4-trans-Abscisic acid (Aldrich Chemie) was dissolved in the nutrient solution at 3 concentrations: $10^{-4}, 10^{-5}$ and $10^{-6} \mathrm{M}$. The nutrient solution supplied to shoots was replaced by an ABA-supplemented one and gas exchange followed for at least 4 more hours.

\section{Effects of $\mathrm{CO}_{2}$ enrichment}

$A, E$ and $g$ were measured successively on $Q$. pubescens under ambient (350) and enriched (1000 $\left.\mu \mathrm{mol} \cdot \mathrm{mol}^{-1}\right) \mathrm{CO}_{2}$ mole fractions, both before and after ABA supply. Each measurement was made after at least $1 \mathrm{~h}$ of equilibration.

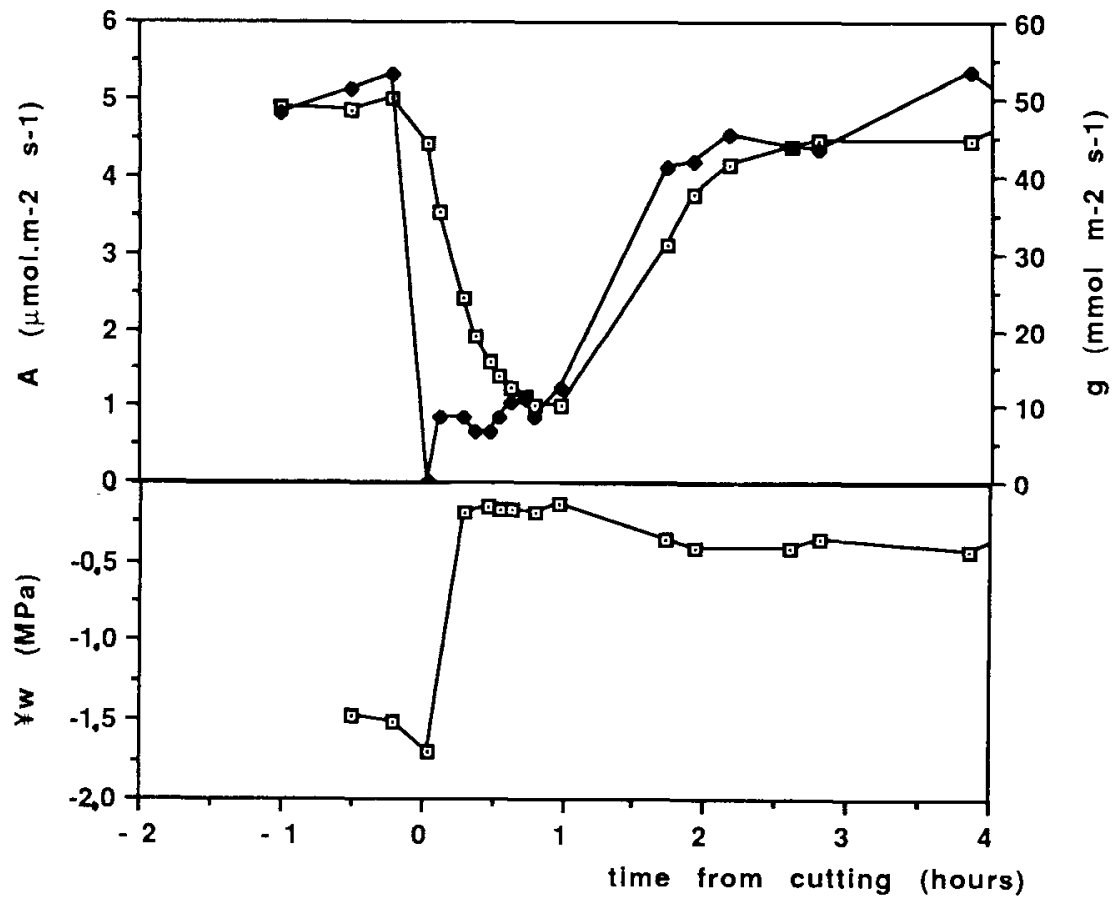

Fig. 1. Effects of cutting a twig and plunging its cut end into a nutrient solution on $A$ (open symbols), $g$ (closed symbols) and $\psi_{w}$ (Q. robur). 


\section{Results}

\section{Effects of cutting}

Cutting caused an immediate and steep decrease in stomatal conductance $(g)$ and net $\mathrm{CO}_{2}$ assimilation (A) (Fig. 1), and a rapid increase of water potential $\left(\psi_{w}\right)$, the latter being a direct consequence of both a reduction in transpiration $(E)$ and the removal of all the resistances to water flux from root to shoots. These effects were immediate (appearing after less than 1 min) and only transient, vanishing in about $1 \mathrm{~h}$. A new steady state was reached thereafter, with significantly lower $A$ and $g$, and was maintained for at least $3-4 \mathrm{~h}$.

In as much as it displays a new steady state gas exchange rate, a cut twig is a valuable tool for studying effects of exogenous ABA in the absence of any water stress.

\section{Effects of $A B A$ application}

At $10^{-4} M$, the effects were very similar to those described above with two main differences: 1) there was a significant time lag before leaf reaction, which may be attributed to ABA diffusion into leaves; from the original records, we may estimate the delay to be $10.8 \pm 1.9 \mathrm{~min}$ for $A$ and $9.1 \pm 1.2 \mathrm{~min}$ for $g$ (Fig. 2a); 2) no recovery appeared during the 1st hours after application, even if $A$ and $g$ increased slightly after the first breakdown. Plotting these results on $A$ vs $c_{i}$ curves (Fig. 2b) reveals a strong reduction of mesophyll photosynthesis.

$A B A$ reactions under increasing external $\mathrm{CO}_{2}$ molar fractions $\left(c_{\mathrm{a}}\right)$

$c_{\text {a }}$ was temporarily increased to 1000 $\mu \mathrm{mol} \cdot \mathrm{mol}^{-1}$ just before and $1 \mathrm{~h}$ after ABA application. Results are shown as $A$ vs $g$ relations ( $Q$. pubescens, Fig. 3). Decreasing reactions with concentrations below $10^{-4} \mathrm{M}$ were observed. Increasing $c_{\mathrm{a}}$ caused additional stomatal closure even in the presence of $A B A$ but did not promote the expected increase in $A$. Furthermore, the application of $A B A$ did not change the relationship between $A$ and $g$ for each $c_{\mathrm{a}}$ : under constant humidity, this suggests that $A B A$ affects both stomatal conductance and mesophyll assimilation.

\section{Discussion}

Cutting promoted quite immediate reactions by leafy shoots. These kinds of effects had been attributed to a hydropassive stomatal closure; but, like Myers et al. (1987) on Eucalyptus sp., we noticed that stomatal closure was accompanied by quasi constant $c_{\mathrm{i}}$ values, which reveals a reduction in mesophyll photosynthetic activity. These effects were reversible and the appearance of a new steady state enabled the use of cut twigs as an experimental tool for ABA studies.

At high concentrations of about $10^{-4} \mathrm{M}$, ABA had an important effect on stomata and photosynthesis on all tested oak species, although lower concentrations $\left(10^{-6}\right.$ M) had no effect.

Direct effects on mesophyll photosynthesis may be inferred from $A$ vs $c_{i}$ curves which show $A$ reductions at constant $c_{\mathrm{i}}$ values, and from the constant $A / g$ ratios at high $c_{\mathrm{a}}$. These results are in agreement with those of Raschke and Hedrich (1985). The $c_{i}$ gradients across hypostomatous leaves (Parkhurst et al., 1985) are not large enough to modify these conclusions. Existence of 'patchy behavior' of stomata in response to ABA (Downton et al., 1988) could contradict these conclusions, but there is still not enough evidence to demonstrate the reality of this behavior. 
a

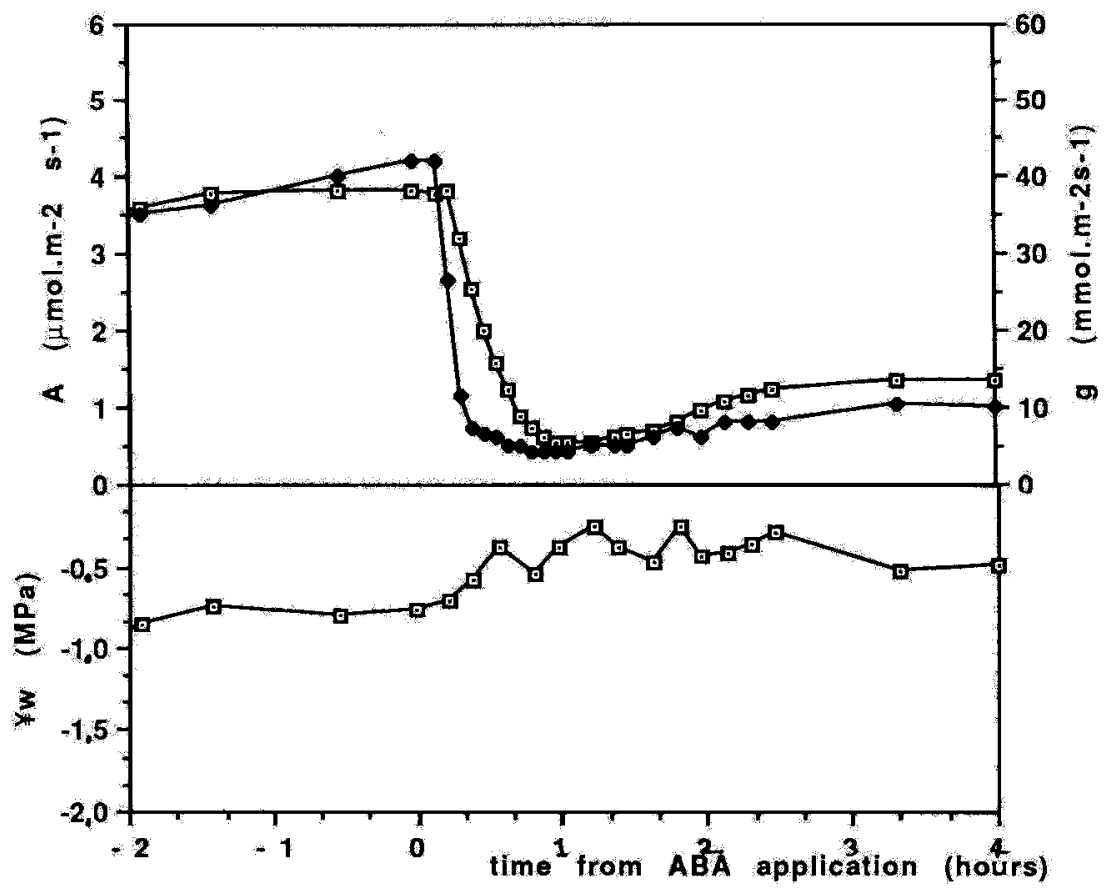

b

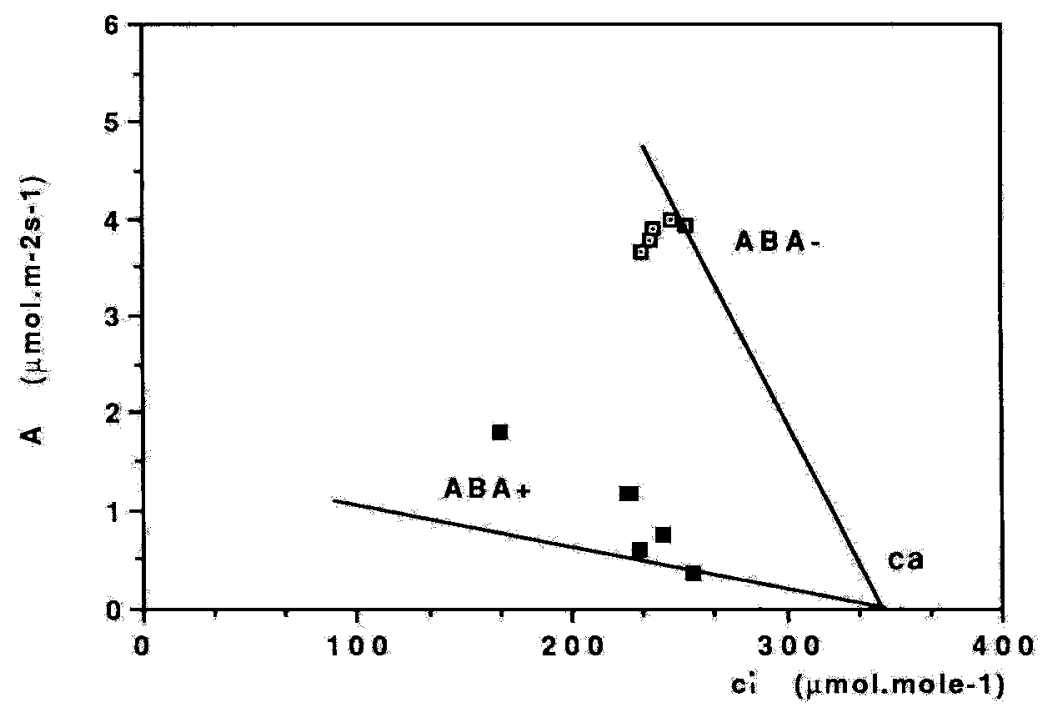

Fig. 2. a. Time course of $A B A$ effects at $10^{-4} \mathrm{M}$ on $A$ (open symbols), $g$ (closed symbols) and $\psi_{w}$ of a cut twig sup. plied with a nutrient solution. b. A vs $c$ curves for same data. Only steady stale values have been sketched to avoid artifacts. 


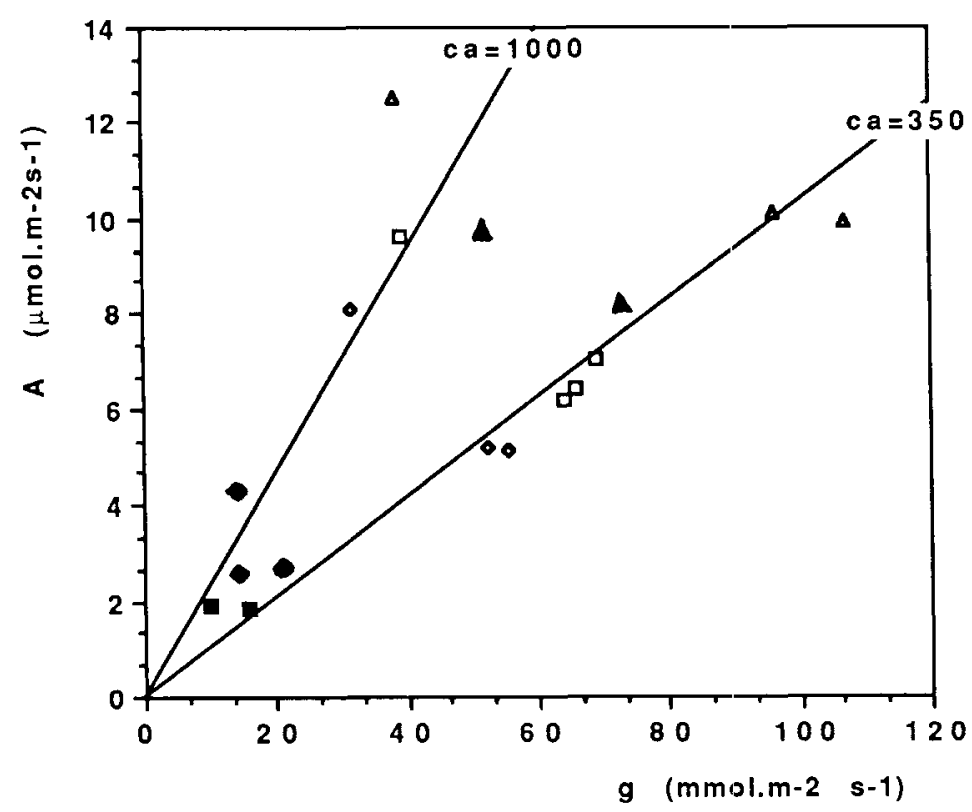

Fig. 3. Relations between $A$ and $g$ under low and high $c_{\mathrm{a}}$. The ABA concentrations were $\square: 10^{-4} \mathrm{M}_{0} \diamond^{\circ} 10^{-5} \mathrm{M}$; $\Delta: 10^{-6} \mathrm{M}$ (open symbols: values before ABA application; closed symbols: after ABA application).

\section{References}

Downton W.J.S., Loveys B.R. \& Grant W.J.R. (1988) Stomatal closure fully accounts for the inhibition of photosynthesis by abscisic acid. New Phytol. 188, 263-266

Johnson J.D. (1987) Stress physiology of forest trees: the role of plant growth regulators. Plant Growth Regul. 6, 193-215

Myers B.A., Küppers M. \& Neales F.T. (1987) Effect of stem excision under water on bulk leaf water potential, leaf conductance $\mathrm{CO}_{2}$ assimilation and stemwood water storage in Eucalyptus behriana F. Muell. Aust. J. Plant Physiol. 14, 135-145
Parkhurst D.F., Wong S.C., Farquhar G.D. \& Cowan I.R. (1938) Gradients of intercellular $\mathrm{CO}_{2}$ levels across the leaf mesophyll. Plant Physiol. 86, 1032-1037

Raschke K. \& Hedrich R. (1985) Simultaneous and independent effects of abscisic acid on stomata and the photosynthetic apparatus in whole leaves. Planta 163, 105-118

von Caemmerer S. \& Farquhar G.D. (1981) Some relationships between the biochemistry of photosynthesis and the gas exchange of leaves. Planta 153, 376-387

Zhang J., Schurr U. \& Davies W.J. (1987) Control of stomatal behaviour by abscisic acid which apparently originates in the roots. J. Exp. Bot. 38, 117.4-1181 